\title{
A influência da Reforma Sanitária na construção das bioéticas brasileiras
}

\author{
The Brazilian Sanitary Reform's influence \\ in the construction of a national bioethics
}

Dora Porto ${ }^{1}$

Volnei Garrafa ${ }^{2}$

${ }^{1}$ Conselho Federal de M edicina. SGAS 915, lote 72, Asa Sul. 70390-150 Brasília DF.

doraporto@gmail.com

${ }^{2}$ Cátedra UNESCO de

Bioética. Núcleo de Estudos

e Pesquisas em Bioética.

Programa de Pós-

Graduação em Bioética.

Campus Universitário

Darcy Ribeiro, Asa N orte.

70919-970 Brasília DF.
Abstract This revision article remakes in general guidelines the path to the Brazilian Bioethics in the planning of research and education autochthones lines from the relations between these lines and the social and historical process that consolidated the Brazilian Sanitary Reform. The works and theoretical perspectives selected have the proposal to act in the some scope, the social dimension; that relate to groups or particularly vulnerable segments that question the power re lationship from the identification of the social inequalities as well as to the ones focused in the same orienting parameters, the H uman Rights treaties; or the ones that included in its themathical rol the discussion about quality of life. The presentation of these distinct points of views of the Brazilian Bioethics are circumscribed at the tangential specifically relationed above and chronologically orientated from the creation of the "Bioethics" term in the North American academic environment.

Key words Bioethics, Society, Brazilian Sanitary Reform, Human rights, Inequalities
Resumo Este artigo de revisão reconstrói em linhas gerais o caminho percorrido pela bioética brasileira na formulação de linhas autóctones de estudo e pesquisa a partir da relação entre essas linhas e o processo histórico e social que consolidou a Reforma Sanitária no país. Foram selecionados os trabalhos e perspectivas teóricas que se propõem a atuar no mesmo âmbito, a dimensão social; que se referem a grupos ou segmentos particularmente vulneráveis; que questionam as relações de poder a partir da identificação das desigualdades sociais, bem como as voltadas para os mesmo parâmetros norteadores, os tratados de direitos humanos, ou ainda aquelas queincluem no rol de sua temática a discussão sobre a qualidade de vida. A apresentação destas distintas visões da bioética brasileira está circunscrita aos pontos tangenciais específicos acima relacionados e orientada cronologicamente a partir da criação do termo "bioética" nos meios acadêmicos estadunidenses. Palavras-chave Bioética, Sociedade, Reforma Sanitária, Direitos humanos, Desigualdade 


\section{Introdução}

Há relação direta entre o processo da Reforma Sanitária brasileira e o perfil da bioética que vem sendo desenvolvida no país. Em ambas as áreas, a análise dos marcos teóricos, âmbitos de atuação, sujeitos aos quais se refere e parâmetros norteadores, o demonstra. A possibilidade de estabelecer paralelo entre esses planos analíticos indica quea reflexão bioética autóctoneno Brasil está sendo direta ou indiretamente influenciada pelas perspectivas delineadas por aquele processo, iniciado há mais de vinte anos.

Se a ReformaSanitária incorporou definitivamente a dimensão social na análise do processo de saúde e adoecimento da população, a bioética brasileira reflete essa preocupação, sendo a principal expressão disso o significativo número de trabalhos publicados recentemente equerelacionam os campos da bioética e da saúde pública ${ }^{1}$.

Paralelo a sua mais expressiva bandeira de reivindicação - a universalização do acesso aos serviços de recuperação da saúde - a Reforma Sanitária enfatizou aspectos da saúde pública determinantes para a qualidade de vida de indivíduos, grupos, segmentos e populações, como ambiente, condições geográficas, acesso à água e alimentação. Tais aspectos passaram, gradativamente, a ser considerados tão importantes para a saúde e a diminuição da morbimortalidade quanto os recursos terapêuticos, especialmente nos casos em que se pôde comprovar que a efetividade da terapêutica havia encontrado seu ponto de saturação, não tendo mais influência na diminuição da relação saúde/adoecimento.

Quando foi possível perceber que o efeito da terapêutica havia deixado de reduzir os índices que mensuram a relação saúde/adoecimento, começam a ser, cada vez mais, incorporados à análise estes outros aspectos que correlacionam saúde à qualidade de vida. Tais aspectos extrapolam o âmbito tradicional da medicina curativa e de suas ferramentas analíticas, bem como de suas áreas prioritárias de produção do conhecimento - a biologia e seus sub-ramos, a química, a farmácia, além da própria medicina e suas especialidades, incluindo a epidemiologia e saúde coletiva - apontando a necessidade de agregar outros campos do conhecimento na busca de soluções para os problemas da saúde.

Sob a influência da Reforma Sanitária, também aspectos relacionados à dimensão socioeconômica, como habitação, renda, trabalho, educação e hábitos pessoais, passaram a ser percebidos como condicionantes do processo, compon- do o recorte analítico sobre esses índices e introduzindo a necessidade de incorporar o conhecimento das ciências humanas, geografia e suas especial idades, ciências sociais, bem como da economia e urbanismo.

Paralelo à análise desses aspectos determinantes e condicionantes da qualidade de vida que atuam na dimensão social e relacionam-se basicamente com a promoção e proteção à saúde, 0 acesso aos serviços passou a ser visto como fundamental, transferindo o foco também no que concerne à recuperação da saúde, a outros fatores não diretamente relacionados à terapêutica. Passaram a fazer parte da reflexão da saúde pública, então, as formas de levantamento e financiamento de recursos, sua alocação e gerenciamento, assim como os resultados das políticas implementadas. Esse enfoque agregou a compe tência das áreas de gestão e administração, propiciando nova destinação ao conhecimento gerado pela estatística e suas ferramentas.

Além da discussão sobre a universalização do acesso, fica evidenciada a necessidade de garantir a qualidade dos serviços para al cançar sua efetividade. A adoção da ideia de qualidade de vida como parâmetro de saúde implicou em introduzir a dimensão subjetiva na análise do processo deadoecimento, permitindo subsidiar os discursos embasados nas noções de diversidade e do conhecimento produzido na área do direito no nível infralegal, constitucional e internacional e, em relação a este, principalmente, a área dos direitos humanos. Esse viés analítico veio ao encontro da ideia de pluralidade moral, noção que também demanda e subsidia a análise qualitativa em saúde pública, considerando as especificidades fisiológicas e comportamentais de grupos e segmentos populacionais, bem como as estratégias coletivas adotadas frente a sua situação e condições de vida.

Decorre da adoção desse viés a incorporação da política como área pertinente à análise dos fatores queinfluenciam a qualidade de vida esaúde das populações. 0 amplo leque de acepções do termo permitiu quea incorporação dessa perspectiva ocorresse sob diversas óticas, abrangendo desdeo arcabouço conceitual gerado nos processos autogestionários dos movimentos sociais, até aqueles relacionados ao estudo das relações formais de poder, centrados na estrutura, atuação e papel do Estado. No caso da Reforma, o Estado tornou-se agente fiduciário na implementação da qualidade de vida como direito de cidadania. A incorporação do campo da política à reflexão da saúde pública favoreceu a inserção 
de ferramentas metodológicas da ciência política, relações internacionais e história.

A introdução da qualidade como parâmetro analítico na área de saúde abriu a discussão sobre a subjetividade em si mesma. A definição de qualidade como estado decorrente da percepção apontou a necessidade de incorporar técnicas e pressupostos analíticos capazes de identificar a subjetividade na dimensão coletiva, expressa em padrões de comportamento, crenças e estruturas simbólicas, como permitem as técnicas e métodos da antropologia. A identificação desses padrões simbólicos ecomportamentais, por suavez, apontou a necessidade de aprofundar essa análise, agregando elementos para tecer considerações de cunho valorativo, como faz a filosofia. Essa breve explanação mostra que, ao longo das últimas décadas, a saúde pública vem agregando conhecimentos de diversas áreas com o intuito de propor processos de transformação social capazes de possibilitar melhor qualidade de vida para indivíduos, grupos, segmentos e populações.

Da mesma maneira, a bioética reproduz essa trajetória, consolidando-se como campo transdisciplinar ${ }^{2}$ de produção de conhecimento, cujo ordenamento metodológico edisciplinar congrega e dialoga com referências de diferentes fontes, articuladas de maneira a descrever, analisar e propor soluções aos impasses éticos que se antepõem à saúde, na acepção ampla de qualidade de vida. Essas distintas perspectivas da bioética brasileira adotam ainda o mesmo âmbito de atuação e a mesma dimensão social; voltam-se à particularização dos mesmos atores sociais, os segmentos e grupos cuja situação e condição de vida implicam a focalização de recursos e estratégias para minimizar a assimetria, e utilizam os mesmo referenciais para identificação desses sujeitos, os conceitos oriundos dos direitos humanos, tomados como norteadores das propostas teóricas.

Nessa linha de ideias, no presente texto, utiliza-se a expressão bioéticas, no plural, de acordo com as conclusões finais do III Encontro LusoBrasileiro de Bioética, desenvolvido na Ilha dos Açores, Portugal, em 2004, cujo tema central trazia a seguinte interrogação: Bioética ou bioéticas na evolução das sociedades? A conclusão foi de que, sendo a bioética plural sob o ponto de vista de moralidades, existem na verdade diversas bioéticas - diferentes e diferenciadas - que devem vencer o desafio de analisar, interpretar e expressar as visões morais do espaço geográfico e social onde são desenvolvidaş.
As origens da bioética

O surgimento da bioética pode ser remetido, entre outras situações históricas, ao Tribunal de Nuremberg, iniciativa dos aliados vencedores da Segunda Guerra M undial para averiguar e julgar os crimes cometidos contra a humanidade pelo governo alemão sob o regime nazista. Disso se pode inferir também que "seu berço é, inegavelmente, a área dos Direitos Humanos" 4 . Porém, a identificação desse campo de estudos por meio do termo "bioética" deu-sesomente 23 anos mais tarde, quando Potter cunhou o neologismo, em 1970, nos Estados Unidos ${ }^{5}$. Na ocasião, sua preocupação voltava-se à discussão dos impactos ambientais da ação antrópica, preocupação que, de maneira geral, começava naquela década a despertar no meio acadêmico em todo mundo. 0 crescimento científico alcançado no pós-guerra havia provocado transformações sociais e ambientais em todas as sociedades industrializadas do O cidente, alterando os modos de vida em cada uma delas.

0 aumento da população mundial a partir do baby boom e a forte tendência de migração para áreas urbanas, desde meados do século XX, contribuíram para acelerar a pressão sobre os recursos naturais. A preocupação com sua proteção e economia foi introduzida não apenas no discurso acadêmico, mas na pauta cotidiana dos veículos de mídia. A apresentação em jornais, revistas e programas televisivos de matérias sobre a poluição do ar e da água, bem como sobre a utilização de combustíveis fósseis, levou ao público leigo o conhecimento, preocupação ediscussão sobre esses temas. É importante considerar que, até então, o crescimento econômico era o único parâmetro para mensurar o desenvolvimento dos países e a ciência e tecnologia vistas como ferramentas indispensáveis e indiscutíveis para produzir o progresso almejado. Segundo Potter, o quelhe interessava era questionar o progresso e para onde os avanços materialistas, próprios da ciência e tecnologia, estavam levando a cultura ocidental ${ }^{5}$.

Se a criação do termo bioética aten deu a uma preocupação com o rumo que a visão de mundo positivista imprimiu à pesquisa científica e ao desenvolvimento tecnológico, os objetivos desua criação não foram contemplados, ao menos nas primeiras duas décadas nas quais essa expressão foi divulgada e utilizada, a partir da perspectiva que imperou na própria sociedade estadunidense. A apropriação do termo no meio médico, por meio das discussões promovidas já em 1971 pelo 
Kennedy Institute of Ethics, implicou em reduzir seu campo de atuação, limitando seu objeto de estudo, métodos e tipos de procedimento, tarefas e finalidades à área biomédica, aos conflitos entre profissionaise pacientes na clínica ou entre pesquisadores e sujeitos de pesquisa. Assim, não foi alcançada a pretensão que originou a iniciativa de Potter, de articular o conhecimento científico natural e a moral humana, as ciências naturais e as ciências sociais, acabando com o pressuposto da "neutralidade axiológica" da ciência preconizada pelo positivismo ${ }^{6}$.

Essa forma de compreender a bioética tornou-se rapidamente hegemônica pela própria difusão desse campo do conhecimento. Facilitou sobremaneira esse processo o Relatório Belmont, produzido pela Comissão Nacional para Proteção dos Seres Humanos em Pesquisa Biomédica e Comportamental, elaborado por determinação do Congresso estadunidense, que delineou como critérios norteadores para a pesquisa biomédica e de comportamento os princípios da autonomia, beneficência e justiça. A posterior incorporação do princípio da não-mal eficência, a partir da obra de Beuchamp e Childress ${ }^{7}$, voltada aos conflitos da prática clínica, e o lançamento da Encyclophedia of bioethic ${ }^{8}$, que definiu o campo da bioética como quase que exclusivamente pertinenteà área biomédica, contribuíram para difundir essa perspectiva, tornando-a predominante. Vale ressaltar, ademais, que esse foco do campo da bioética na área biomédica acompanhou o crescimento vertiginoso da indústria de medicamentos, que, nesse período, tornou-se um dos setores mais rentáveis da economia mundial.

O surgimento da bioética brasileira no marco da saúde pública

O Brasil demorou mais de vinte anos para incorporar formalmente a bioética como um campo de estudos e mais outros tantos para começar a rever eadaptar à realidade brasileira as propostas discutidas mundialmente: "a bioética brasileira é tardia, tendo surgido de forma orgânica somente nos anos 1990"9. Deve-se considerar, no entanto, que nessa época o país esteve sob a ditadura militar, o que torna compreensível o largo período que a bioética levou para se consolidar no Brasil. Ainda que possam haver outras razões, o jugo da ditadura pode ser considerado motivo mais que suficiente para dificultar a introdução no país de um campo de estudo que se propõe a discutir a ética das relações e inter-relações, sejam elas pertinentes à área biomédica ou não, assim como as razões que determinam vida e morte de indivíduos, grupos, segmentos e populações.

Há que se salientar, também, a influência determinante do contexto político e econômico mundial, quenesse período da expansão do mercado globalizado provocou a retração das políticas sociais dos Estados-nação, repercutindo diretamente no setor saúde. A crise econômica, social, política e cultural que se seguiu a essas transformações macroeconômicas, implicaram o esgotamento das condições para manutenção do Estado de Bem-Estar Social (Welfare State) que, direta ou indiretamente, orientava os modelos de políticas públicas, mesmo nos países "em desenvolvimento", como o Brasil.

A constatação de que os vultosos investimentos na área da saúde não tinham alcançado os objetivos esperados polarizou eagudizou a tensão da discussão que se seguiu. Essa discussão apontava dois caminhos distintos para responder à crise sanitária: por um lado, havia os que tendiam a orientar a polêmica para os efeitos danosos da intervenção estatal nas políticas públicas, aproveitando os limites impostos pela crise econômica e pelos interesses de mercado. Por outro, estavam aqueles que acreditavam numa ordem política provida ou mediada pelo Estado e buscavam trazer para a arena de discussão sua própria visão sobre a relação entre pobreza e saúde ${ }^{10}$.

A repercussão da crise econômica no Brasil acabou por fortalecer um movimento contrahegemônico na saúde que, no final dos anos setenta e início dos oitenta, consolidou-se no projeto da Reforma Sanitária brasileira: Em todo país surgem movimentos detrabalhadores de saúde. São criados o Centro Brasileiro de Estudos em Saúde (Cebes) e a Associação Brasileira de Pós-Graduação em Saúde Coletiva (Abrasco), que participaram do processo desistematização das propostas de mudança do modelo de saúde em vigor ${ }^{11}$. Deve-se ressaltar que foram relevantes, na construção desse processo, a Declaração de Alma-Ata para os Cuidados Primários em Saúde de 1978 e, na década de oitenta, o Relatório Lalonde, produzido pelo governo do Canadá, assim como, posteriormente, as Conferências de Ottawa, Adelaide e Sunsvall e seus respectivos conjuntos de recomendações ${ }^{12}$. Esses documentos introduziram conceitos como o de equidade no acesso ${ }^{10} \mathrm{e}$ ideias como promoção à saúde ${ }^{13}$, as quais, posteriormente, foram incorporadas como princípios, diretrizes ou objetivos do Sistema Ú nico de Saúde (SUS). Os pressupostos teóricos e metodoló- 
gicos da Epidemiologia Social também se configuraram como elementos importantes para resgatar e legitimar um corpo de conhecimento em saúde voltado às práticas coletivas.

Em 1986, a VIII Conferência N acional deSaúde formaliza proposta para a construção de um modelo para a saúde, o qual serviu de base para as discussões da Assembleia Nacional Constituinte. 0 artigo 196 da Constituição da República Federativa do Brasil, promulgada em 1988, reconhece a saúde como um direito de cidadania a ser garantido pelo Estado, instaurando a base para a criação do SU ${ }^{14}$. O conceito de saúde incorporado pelo SUS implicou em perceber saúde de forma ampliada, considerando fatores sociais, econômicos e ambientais como condicionantes da relação entre saúde e adoecimento. Tal forma ampliada de classificar os fenômenos que concorrem para a relação saúde e adoecimento deu origem aos três níveis de atenção preconizados pelo SUS, voltados a promover, prevenir e recuperar a saúde.

Entretanto, essa forma ampliada de definir e lidar com a saúde, proposta pelo SUS, não foi imediatamente absorvida no campo da bioética, que nessa ocasião começava a ser introduzida no país. A influência da perspectiva estadunidense, hegemônica em todo mundo naquele momento, condicionou fortementea importação acrítica do modelo principialista debioética. Alinhado a uma visão demundo reducionista e conservadora, que negava, inclusive, o ensinamento hipocrático, que "consiste sobretudo em reconhecer queexisteuma continuidade entre as doenças do indivíduo e as doenças da coletividade"15, tal modelo apenas fortal ecia a ideia de saúde construída a partir dos interesses de mercado e das respostas individuais e medicalizadas ao adoecimento.

M esmo que indiretamente, a adoção unívoca do modelo principialista como sinônimo debioé tica acabava por conferir-Ihe âmbito excessivamente restrito. Ao reduzir a discussão bioética à dimensão individual e focar a reflexão nos aspectos éticos relacionadosà saúdee adoecimento apenas na clínica ena pesquisa, a bioética contribuía para subsumir a dimensão social, desconsiderando a importância do ambiente, condições geográficas, acesso à água, alimentação, habitação; de condicionantes relacionados à dimensão socioe conômica, como renda, trabalho, educação e hábitos pessoais, e ainda de fatores decorrentes do acesso aos serviços de saúde. Assim, a bioéticatornava-se uma ferramenta asséptica, que não questionava as relações de poder, a ética ou a moralidadena dimen são social, nem associava tais questões ao processo de saúde e adoecimento.
A fundação da Sociedade Brasileira de Bioética (SBB), em 1995, pouco alterou esse quadro. Exemplifica essa afirmação o texto das Diretrizes e Normas Regulamentadoras de Pesquisa Envolvendo Seres Humanos, Resolução do Conselho Nacional de Saúde RN-CNS196/1996, cujo preâmbulo especifica os quatro princípios, identificando-os como "os referenciais básicos da bioética"16. Essa resolução foi produzida por um grupo de trabalho composto, na sua maioria, por membros da SBB. Disso se constata que, também no Brasil, o principialismo era identificado como "o próprio coração da bioética" ${ }^{17}$. De fato, a aceitação inconteste desta perspectiva ainda é tão marcante que, mesmo quando se pretende não caracterizar um alinhamento total ao principialismo, pesquisadores brasileiros na área ainda se referem de modo unilateral aos "princípios da bioética"18.

Esse reducionismo à área biomédica no âmbito de atuação, nas temáticas tratadas e na focalização dos sujeitos aos quais se refere a bioética, acarretou sérias implicações epistemológicas e metodológicas. Por ser vista como um acessório destinado a regular as falhas dos códigos deontológicos das profissões biomédicas, esse campo passou a atuar quase que exclusivamente como um "poder moderador", capaz de arbitrar sobre conflitos éticos em casos e circunstâncias específicas, voltado, assim, a regular (ou minimizar) os danos na pesquisa e aplicação das biociências e da biotecnologia. A adoção dessa perspectiva refletiu-se também na própria pesquisa em bioética que, em decorrência de sua relação direta e exclusiva com a área biomédica, passou a ser validada e reconhecida apenas na medida em que reproduzisse os métodos e técnicas comumente utilizadas nessas áreas.

Tal orientação, no entanto, acabou por encontrar resistência até mesmo entre os que atuavam nesse campo, que a partir desse momento começaram a se autodesignar "bioeticistas". A desconstrução do principialismo e a construção deuma rel ação politizada ecrítica entrebioéticae saúde pública já vinham sendo trabalhadas no Brasil por estudiosos desse campo, oriundos do movimento sanitário eque tinham produção científica comprometida com o campo social. Duas referênciasnessecontexto histórico são: A dimensão da ética em saúde pública, produzido na Universidade de Brasília e publicado em 199519; e A terceira margem da saúde, da Escola Nacional de Saúde Pública da Fundação O swaldo Cruz, publicado em $1996^{20}$. A partir desse período, a bioética brasileira passou a ser identificada com uma 
ótica que parte da experiência de um grande país do H emisfério Sul, rico em movimentos populares e experiências culturais, e atormentado pela pobreza epela injustiça, sem ficar aprisionada àsfronteiras ou limites mas, ao contrário, ligando-se às tradições fil losóficas européi as e ao debate bioético internacional ${ }^{21}$.

Estas iniciativas foram rapidamente seguidas por outras tentativas de contextualizar o debate nesse campo à realidade nacional. Os pesquisadores que se opunham à adoção irrestrita da perspectiva principialista voltaram sua atenção ao resgate dos conceitos da saúde coletiva, buscando responder aos conflitos que emergiam da nova forma de atenção proposta pelo SUS. Propugnando transformações no status quo, somaramse às discussões sobre saúde pública e equidade na alocação de recursos, que já apontavam para o questionamento, aprofundado posteriormente, sobre o rumo do desenvolvimento tecnológico na área da saúde e para a problemática da desigualdade de direito ao acesso aos bens e serviços que caracterizam a qualidade de vida: A igualdade é a consequência desejada da equidade, sendo o ponto de partida para aquela. Ou seja, é somente com o reconhecimento das diferenças e das necessidades diversas dos sujeitos sociais que se podealcançar a igualdade. A igualdade não é mais um ponto de partida ideológico que tendia a anular as dife renças. A igualdadeéo ponto de chegada da justiça social, o referencial dos Direitos $\mathrm{H}$ umanos e o passo que precede o reconhecimento da cidadania ${ }^{22}$.

Embora tateantes a princípio, as iniciativas para construir uma perspectiva autóctone para a bioética brasileira nesse período já apontavam a divergência em relação à perspectiva estadunidense. 0 questionamento ao modelo principialista, comparado por alguns dos seus críticos a um checklist normativo ${ }^{21}$, era identificado pelos bioeticistas brasileiros como argumentação contrária a essa visão focada exclusivamentenas práticas curativas. Começava a ser questionada a perspectiva individualista desse modelo, alicerçado na autonomia individual, que deixava de perceber, admitir ou ponderar sobre a ética e os juízos morais em saúde na dimensão coletiva. Em relação à pesquisa em bioética, tal orientação também encontrou resistência, principalmente porque dificilmentese pode- defato - apreender os valores que orientam as moralidades apenas por estudos quantitativos.

De maneira geral, pode-se dizer que esses esforços para contextualizar esistematizar a bioética no Brasil buscavam uma aproximação entrea discussão voltada exclusivamente à atenção à saúde e o panorama socioeconômico do país, o qual condiciona a produção da saúde e do adoecimento.

\section{Bioética da Teologia da Libertação}

Tendo como base os movimentos sociais ligados à I greja Católica e à Teologia da Libertação, a bioética da Teologia da Libertação foi a primeira construção teórica brasileira a identificar claramente a vulnerabilidade na dimensão social, associando-a à pobreza e exclusão, já na década de noventa, a partir da classificação dos conflitos éticos como pertinentes às dimensões micro, midi e macrossocial ${ }^{23}$. Apesar da matriz teórica de origem religiosa, essa perspectiva propõe 0 diálogo com a bioética laica, pois para esta vertente o discurso teológico não se restringe à comunidade interna das igrejas, "podendo assim colaborar na desconstrução do modelo injusto da sociedade capitalista" 24 .

Refletindo a perspectiva em voga na fase inicial de seu delineamento, essa vertente circunscreve o âmbito deação da bioética à discussão da ética na área biomédica, apontando, porém, os grandes contrastes entre ricos e pobres, que evidenciam que [...] a doença e a morte têm raízes sociais na fome, na insalubridade da moradia, na falta de saneamento básico, de água e esgoto, nas precárias condi ções de trabalho, na falta de educação sobre os cuidados sanitários e mesmo na falta de condições econômicas para pô-los em prática ${ }^{25}$.

Avançando a argumentação em direção à crítica das razões políticas e econômicas que originam as desigualdades sociais, a bioética da Teologia da Libertação salienta que mesmo aceitando que possam haver razões de cunho epistemológico para não se fazer bioética no nível da Política e da Economia, persiste entretanto a necessidade de, no mínimo, fazer bioética em diálogo com a ética social ${ }^{26}$. Tal argumentação abriu caminho para a legitimação da problemática social no campo da bioética, enfatizando a importância do diálogo com os segmentos excluídos eda implementação de programas permanentes de Estado para a construção da cidadania ${ }^{27}$.

\section{Bioética de proteção}

Outra vertenteteórica bem mais recente, mas que também trabal ha a problemática da exclusão social, é a bioética da proteção ${ }^{28}$. Caracterizada como uma proposta que abrange dois âmbitos de atuação distintos, implicados na maior ou 
menor amplitude da ideia de proteção, essa perspectiva volta-se para a necessidade de desenvolver "fundamentos e métodos capazes de analisar e validar os dilemas e as propostas específicas no âmbito da saúde pública"29. Advoga, também, a importância do Estado, atribuindo-Ihe o papel de proteger a integridade física e patrimonial de seus cidadãos e de assegurar-Ihes qualidade de vida, respeito às liberdades públicas e à autonomia individual.

A bioética da proteção propugna o reconhecimento da garantia da qualidade de vida como um componenteessencial dasfunções do Estado, considerando a necessidade de proteger grupos específicos em situação de vulnerabilidade extrema. A ideia de proteção é trabalhada de forma polissê mica, que confere o duplo âmbito de atuação à ideia de proteger, propondo tanto dar amparo aos excluídos das políticas públicas por meio demedidas compensatórias de saúde quanto, ao mesmo tempo, na dimensão ampliada do conceito, atuar propositivamente a fim de elaborar um projeto coletivo de transformação sociopolítica ${ }^{30}$.

É importanteressaltar que, embora preconize a necessidade de proteção aos vulneráveis/vulnerados, numa perspectiva vertical associadaà atenção do Estado aos problemas de saúde pública ${ }^{28}$, a bioética da proteção reconhece a importância de preservar e fomentar a autonomia individual como meio de construir formas de participação social libertárias nas políticas de saúde ${ }^{29}$.

\section{Bioética feminista e antirracista}

No que concerne especificamente à discussão de gênero, e com características originais e próprias, não se pode deixar de fazer referência à bioé ticafeminista eantirracista, vertentequese origina dos movimentos sociais e propõe novos parâmetros para o comportamento das mulherese dos homens na sociedade. Essa perspectiva da bioética enfatiza quea inserção social das mulheres nas sociedades contemporâneas não deve "permanecer subjugada à dominação masculina, que fragiliza, oprime vulnerabiliza a condição feminina" ${ }^{\prime 1}$.

A bioética feminista e antirracista volta-se à discussão das condições de vida das mulheres e das situações que afetam diretamente suas vidas em decorrência dos papéis sociais a elas atribuí$\operatorname{dos}^{4,32,33}$. Porém, se na dimensão social o Movimento Negro apontou suas diferenças em relação ao feminismo brasileiro, criticando o foco de suas discussões, exclusivamente centrado nos pro- blemas vivenciados pelas mulheres brancas das classes média ealta, a bioética feminista eantirracista refletiu tal cisão. Apontando como decorrência do racismo as flagrantes distinções entreas condições de vida das mulheres negras e brancas e associando à discriminação por cor, inclusive, a situação de pobreza ou riqueza das mulheres, consequentemente, as desigualdades no acesso aos bense serviços entre elas, essa vertente da bioética politizou o discurso feminista em bioética, contextualizando-o à realidade brasileira e ampliando-o aos mais diversos segmentos sociais.

A bioética feminista e antirracista critica 0 generalismo ético da bioética acadêmica, incapaz de vincular-se concretamente às demandas sociais dos segmentos discriminados. Enfatiza, também, que o estatuto epistemológico da bioética hegemônica fez prevalecer uma perspectiva apolítica que até hoje influencia esse campo ${ }^{34}$.

\section{Bioética de intervenção}

A classificação dos conflitos éticosem saúde como persistentes e emergentes ${ }^{35}$ ea denominação bioética dura ${ }^{36}$ precederam a construção da bioética de intervençãa ${ }^{37}$. Essa perspectiva pretende canalizar seus esforços de construção epistemológicae metodológica para abranger também a dimensão social: A bioética de intervenção delineia-se a partir do reconhecimento da ideia de saúde como qualidade de vida, expandindo-se em direção ao reconhecimento do contexto social como campo legítimo de estudos e intervenção bioéticos ${ }^{38}$.

No que diz respeito aos sujeitos aos quais se refere (ou deveria se referir a bioética, segundo a interpretação dessa vertente), a bioética de intervenção entendea necessidade de abarcar a totalidade dos sujeitos sociais, analisando as relações de poder entre os indivíduos, grupos e segmentos e os padrões éticos que orientam tais relações. Considera queéa articulação entre os diferentes grupos e segmentos o que transforma um mero aglomerado de indivíduos em uma socie dade ${ }^{39}$, tal como apontam as bases da sociologia.

Devido às enormes e aviltantes desigual dades socioeconômicas que impactam a realidade nacional, a supressão de um substancial contingente populacional do processo produtivo e a exclusão da maioria dos brasileiros das condições que caracterizam a qualidade de vida, e, considerando ainda a importância de fomentar e fortalecer a noção coletiva de pertencimento a uma mesma sociedade, moldada sob a égide de uma cidadania em comum partilhada por todos, a bioética de 
intervenção preconiza como moralmente justificável na esfera pública a priorização de políticas que privilegiem o maior número de pessoas, pelo o maior tempo possível e que resultem no bem comum, ou seja, "nas melhores consequências para toda a coletividade" 38 . No campo privado e na dimensão individual, aponta para a necessidade de fomentar a libertação $0^{40}$, sustentar o empoderamento ${ }^{41}$ e assegurar a emancipação dos sujeitos sociais, buscando assim alcançar sua inclusão plena na dinâmica relacional da sociedade ${ }^{42}$.

$A$ bioética deintervenção defende a ideia que a concretude social émanifesta no corpo das pessoas cuja totalidade somática materializa e sustém a vida social, em toda e qualquer sociedade, permitindo a existência da coletividade, pois não existecorpo indi vidual que não seja partedo corpo social e, nesse sentido, a noção de corporeidade está intimamente ligada à percepção do eu eà construção da persona. Assim, a corporeidade, na qual estão articuladas as dimensões física e psíquica, que se manifestam de maneira integrada nas inter-relações sociais e nas relações com 0 ambiente, ou seja, na existência concreta da pessoa, é o marco a partir do qual se pode definir a necessidade da intervenção bioética.

A definição do corpo como critério para a intervenção relaciona-se diretamente ao fato da experiência corpórea ser modulada pela dor e pelo prazer, que atuam como marcadores somáticos autorregulados, uma vez que, em geral, os seres humanos buscam aproximar-se do que desperta prazer e afastar-se do que provoca dor. Para perceber edefinir o queéfundamental à vida do indivíduo e da sociedade, ou seja, os elementos que identificam a qualidade devida, deve-serecorrer a esse universal óbvio, considerando as funções essenciaisà existênciado ser e, principalmente, a projeção na dimensão coletiva desseenteconcreto, sintetizada na condição de pessoa. Dessa forma, prazer e dor podem se tornar indicadores da intervenção à medida querefletem a satisfação (ou não) das necessidades desujeitos concretos em uma determinada sociedade, cultura e tempo.

A bioética de intervenção considera os tratados internacionais de direitos humanos os parâmetros norteadores para essas estratégias de intervenção. A proposta de intervenção formulada a partir desses tratados está ancorada no reconhecimento de que tais documentos expressam consensualmentea moralidade coletiva na dimensão mundial ou, ao menos, a expectativa dos países em atingir essa moralidade ${ }^{42}$.

Seguindo as recomendações desses tratados, a intervenção deve ocorrer para preservar para todos os seres humanos os direitos de primeira geração, relacionados ao reconhecimento da condição de pessoa como requisito único, universal e exclusivo para a titularidade de direitos, considerando-se direito inalienável a sobrevivência física e social dos seres humanos ${ }^{38}$. Também são parâmetros orientadores os direitos de segunda ge ração, econômicos esociais, que dizem respeito à diferença entre 0 simples existir e 0 viver, e se relacionam à qualidade de vida. Quanto a esse rol de direitos, a bioética de intervenção salienta a importância de aten der às necessidades específicas dos grupos e "segmentos historicamente vulneráveis pela situação e condição de vida desfavorável na qual se encontram"38.

Essa vertente se orienta também pelos direitos de terceira geração, relacionados à preservação do ambiente e dos recursos naturais. Esses direitos apontam para a necessidade de superar o paradigma antropocêntrico e tomar como imperativo categórico a necessidade urgente de reavaliar prioridades, tanto na produção de bens quanto na redução do consumo ${ }^{38}$.

Considerando tanto a perspectiva da equidade na dimensão social quanto a finitude dos recursos naturais na perspectiva ambiental, a bioética de intervenção propõe que a relação entre os direitos de primeira, segunda e terceira geração desenhe-se sobre um pressuposto ético universal, calcado em uma [...] linha demarcatória que define 0 essencial [e] aponta tanto 0 que deve ser garantido para suprir as necessi dades do empobrecimento quanto o que deve ser suprimido para eliminar o supérfluo da superabundância para indivíduos, grupos, segmentos e populações submetidos a tais condições. Assim, aumentando o insuficiente e diminuindo 0 excedente, se completa 0 ciclo da equidade, garantindo a sustentabilidade social e ambiental e a vida de todos. Isso é, pura e simplesmente, justiça ${ }^{38}$.

Se os referenciais orientadores da bioética de intervenção estão embasados nos diversos tratados internacionais de direitos humanos, a proposta deinterven ção formulada a partir deles está ancorada no reconhecimento de que tais documentos expressam consensualmente a moralidade coletiva na dimensão mundial ${ }^{43}$.

\section{Considerações finais}

A sucinta apresentação das linhas autóctones da bioética brasileira relacionadas ou influenciadas pelo processo da Reforma Sanitária aqui apre sentada permite não apenas perceber a influên- 
cia destaúltima no âmbito etemática da reflexão bioética, como também a interface da bioética com a saúde pública.

Tal interface é perceptível no delineamento conceitual, campo de atuação, no objeto de estudo, tarefas e finalidades que se podem estabelecer entre elas. Dado o lapso temporal entre os dois acontecimentos e o fato de que a maioria dos bioeticistas que vêm desenvolvendo essas linhas de estudo e pesquisa no Brasil terem, anteriormente, militado naquelemovimento, contribui para consolidar essa identidade entre os dois processos.

Além disso, como apontam Oliveira et al. ${ }^{30}$, pode-se constatar também certa unidade interna nas vertentes da própria bioética. Tanto a bioética da Teologia da Libertação, quanto a bioé tica da proteção, a bioética feminista eantirracista e também a bioética de intervenção, referemsea sujeitos particulares que, por condições sociais, econômicas e culturais específicas, têm seus direitos de cidadania subsumidos. Esses sujeitos são respectivamente identificados por essas vertentes como excluídos, vulnerados, oprimidos, vítimas das relações assimétricas de gênero, do racismo por cor e etnia, ou, simplesmente, como os grupos e segmentos ou populações pobres, que no âmbito interno das nações ou na relação entre elas, são apartados das condições sociais e ambientais que caracterizam a qualidade devida.

É possível constatar, ainda, a identidade entre essas perspectivas, no que diz respeito ao reconhecimento da dignidade humana como valor inerente e inalienável, o que as reporta aos pressupostos subjacentes à Reforma Sanitária e ao marco dos direitos humanos.

Nesse sentido, as formas de atuação preconizadas para os sujeitos sociais por essas distintas perspectivas estão delineadas, em todas elas, segundo recomendam os tratados de direitos humanos. Essas formas são classificadas como inserção comunitária, participação social em movimentos voltados à luta pela garantia de direitos de grupos e segmentos específicos eà imple- mentação de políticas afirmativas, ou à busca de sua libertação, empoderamento e emancipação, seja de forma autogestionária ou por medidas de compensação e proteção do Estado.

0 discurso sanitário da bioética brasileira, re presentado nas discussões desenvolvidas neste artigo, fica reconhecido na prática com a homologação, em 2005, da Declaração Universal sobre Bioética eDireitos Humanos da Unesco ${ }^{44}$, no qual a representação do Brasil - seguindo a linha dos bioeticistas-sanitaristas nacionais- exerceu papel decisivo. A declaração incluiu fortemente as questões sanitárias e sociais. Seu artigo 14, especificamente, quetrata da"responsabilidade social esaúde", define que a promoção da saúdee do desenvolvimento social para sua população éo objetivo central dos governos, partilhado por todos os setores da sociedade. 0 item seguinte do mesmo artigo complementa a inserção da saúde pública nos referenciais da bioética, reforçando queusufruir o mais alto padrão de saúde éum dos direitos fundamentais do ser humano equepara isso o acesso a cuidados de saúde de qualidade ea medicamentos essenciais deve ser garantido para todas as pessoas. Para o mesmo fim, recomenda 0 acesso à nutrição ade quada eágua de boa qualidade; a melhoria dascondições de vida e do meio ambiente; a eliminação da marginalização e exclusão de indivíduos; e a redução da pobreza e do analfabetismo.

Tudo isso permite constatar que a bioética brasileira está se construindo de maneira articulada com os movimentos sociais, voltada aos interesses das pessoas concretas, os atores sociais que produzem e reproduzem a dinâmica da sociedade na dimensão de seus corpos e suas vidas. Permite perceber, também, que tal construção autóctone reflete organicidade histórica em relação à Reforma Sanitária, que concorre para o ajuste ou adequação das tarefas e finalidades e implica admitir que as ferramentas delineadas por cada uma dessas perspectivas da bioética brasileira são potencialmente capazes para responder aos conflitos éticos na saúde pública.

\section{Colaboradores}

D Porto e V Garrafa participaram, igualmente, de todas as etapas de elaboração do artigo. 


\section{Referências}

1. Schramm FR, Anjos MF, Zoboli E. A questão das tendências epistemológicas ou de fundamentação. In: Anjos M F, Siqueira JE, organizadores. Bioética no Brasil - Tendências e Perspectivas. São Paulo: Ideias e Letras/Sociedade Brasileira de Bioética; 2007. p. 29-56.

2. Garrafa V. Multi-inter-transdisciplinaridade, complexidade e totalidade concreta em bioética. In: Garrafa V, Kottow M , Saada A, organizadores. Bases conceituais da Bioética - enfoque latinoamericano. São Paulo: Gaia/Unesco; 2006. p. 73-91.

3. Neves M CP, Lima M. Bioética ou bioéticas na evolução das sociedades. Coimbra: Gráfica de Coimbra; 2005.

4. Oliveira M F. Por uma bioética não-sexista, anti-racista e libertária. Dossiê. São Paulo: Rede Feminista de Saúde Direitos Sexuais e Direitos Reprodutivos; 2000.

5. Potter VR. Bioethics, the science of survival. Perspectives in Biology and M edicine 1970; 14:127-153.

6. Sotolongo PL. El tema de la complejidad en el contexto de la bioética. In: Garrafa V, Kottow M, Saada A, organizadores. Estatuto epistemológico de la bioé tica. M éxico: Unam/Unesco; 2005. p. 95-123.

7. Beauchamp T, Childress J. Principles of biomedical ethics. New York, Oxford: Oxford University Press: 1979.

8. Reich W, editor. Encyclopedia of bioethics. New York: Macmillan; 1978.

9. Garrafa V. Radiografia bioética de Brasil. Acta Bioethica 2000; 6(1):165-169.

10. Almeida C. Saúde nas reformas contemporâneas. In: Costa AM, M erchán-Hamann E, Tajer D, organizadores. Saúde, equidade e gênero - um desafio para as políticas públicas. Brasília: Editora Universidade de Brasília; 2000. p. 61-93.

11. Cunha JPP, Cunha RE. Sistema Único de Saúde Princípios. In: Mendes JCC, organizador. Gestão M unicipal de Saúde - textos básicos. Rio de Janeiro: Ministério da Saúde; 2001. p. 285-304.

12. Ferreira JR, Buss PM. Atenção primária e promoção da saúde. In: M endes JCC, organizador. Gestão M unicipal de Saúde - textos básicos. Rio de Janeiro: M inistério da Saúde; 2001. p. 255-263.

13. Andrade OLM, Barreto ICHC. Promoção da saúde e cidades/municípios saudáveis: propostas de articulação entre saúde e ambiente. In: M inayo MCS, M iranda AC, organizadores. Saúde e ambiente sustentável - estreitando nós. Rio de Janeiro: Fiocruz; 2000. p. 151-171.

14. Brasil. Constituição da República Federativa do Brasil. Brasília: Senado Federal; 1988.
15. Berlinguer G. Questões de vida: ética, ciência e saúde. São Paulo: APCE/H ucitec/CEBES; 1993.

16. Brasil. Conselho Nacional de Saúde. N ormas para pesquisa envolvendo seres humanos. Brasília: Ministério da Saúde/Comissão Nacional de Ética em Pesquisa; 2000. p. 22-23.

17. Junges JR. Ética e consentimento informado. Cadernos de Ética em Pesquisa 2000; II(4): 22.

18. Freitas CBD, Hossne WS. O papel dos comitês de ética em pesquisa e proteção do ser humano. Bioé tica 2002; 10(2):129-146.

19. Garrafa V. Dimensão da ética em saúde pública. São Paulo: Faculdade de Saúde Pública USP/Kellogg Foundation; 1995.

20. Schramm FR. A terceira margem da saúde. Brasília: Editora UnB; 1996.

21. Garrafa V, Oselka G, Diniz D. Saúde pública, bioé tica e equidade. Bioética 1997; 5(1):27-33.

22. Diniz D, Guilhem D, Garrafa V. Bioethics in Brazil. Bioethics 1999; 13(3-4):243-248.

23. Anjos M F. Bioética, abrangência e dinamismo. 0 M undo da Saúde 1997; 21(1):11.

24. Siqueira JE, Porto D, Fortes PAC. Linhas temáticas da bioética no Brasil. In: Anjos M F, Siqueira JE, organizadores. Bioética no Brasil - Tendências e Perspectivas. São Paulo: Ideias e Letras/Sociedade Brasileira de Bioética; 2007. p. 174.

25. Anjos M F. Teologia da libertação e bioética. In: Privitera S. Dicionário de bioética. A parecida: Santuário; 2000.

26. Anjos MF. Bioethics in a liberationistic key. In: Dubose $\mathrm{E}, \mathrm{H}$ amel R, O'Connell L, editors. A matter of principles? Ferment in U.S. bioethics. USA: Trinity Press International/ Valley Forge; 1994. p. 130-147.

27. Anjos M F. Bioética nas desigualdades sociais. In: Garrafa V, Costa SIF, organizadores. A bioética no século XXI. Brasília: Editora UnB; 2000. p. 49-65.

28. Schramm FR, Kottow M. Princípios bioéticos en salud pública: limitaciones y propuestas. Cad Saude Publica 2001; 17(4):949-956.

29. Schramm FR. Proteger os vulnerados e não intervir aonde não se deve. Revista Brasileira de Bioética 2007; 3(3):401-413.

30. Schramm FR. Bioética sem universalidade? Justificação de uma bioética latino-americana e caribenha de proteção. In: Garrafa V, Kottow M, Saada A, organizadores. Estatuto epistemológico de la bioética. M éxico: Unam/Unesco; 2005. p. 143-157.

31. Oliveira AAS, Villapouca KC, Barroso W. Perspectivas epistemológicas da bioética brasileira a partir da teoria de Thomas Kuhn. Revista Brasileira de Bioética 2005; 1(4):363-385. 
32. Oliveira M F. Bioética: uma face da cidadania. São Paulo: Moderna; 1997.

33. Oliveira MF. Opressão de gênero, feminismo e bioética: algumas considerações para o debate. M esa Redonda Gênero e bioética. RAGCyT - Red Argentina de Gênero, Ciência y Tecnologia; 1998; Buenos Aires.

34. Oliveira M F. Feminismo, raça/etnia, pobreza e bioética: a busca da justiça de gênero, anti-racista e de classe. In: Garrafa V, Pessini L, organizadores. Bioética: poder e injustiça. São Paulo: Loyola; 2003. p. 345-363.

35. Garrafa V. Bioéticas, salud y ciudadania. Salud problema y debate 1997; 9(16):26-33.

36. Garrafa V. Bioética fuerte - una perspectiva perifé rica a las teorías bioéticas tradicionales. 3er. Congreso de Bioética de América Latina y del Caribe; 2000; Panamá.

37. Garrafa V, Porto D. Intervention bioethics: a proposal for peripheral countries in a context of power and injustice. Bioethics 2003; 17(5-6):399-416.

38. Porto D, Garrafa V. Bioética de intervenção: considerações sobre a economia de mercado. Bioética 2005; 13(1):111-123.

39. Durkheim E. As regras do método sociológico. São Paulo: Companhia Editora Nacional; 1990.

40. Freire P. Pedagogia da autonomia. São Paulo: Paz e Terra; 2001.

41. Sen A. Desenvolvimento como liberdade. São Paulo: Companhia das Letras; 2000.

42. Garrafa V. Inclusão social no contexto político da bioética. Revista Brasileira de Bioética 2005; 1(2):122132.

43. Porto D, Tapajós A. Gênero, raça e bioética de intervenção. In: Anais do V Congresso Brasileiro de Bioética. 2004; Recife. p. 26.

44. Unesco. Declaração U niversal sobre Bioética e Direitos Humanos. Tradução brasileira: Cátedra Unesco de Bioética a Universidade de Brasília. [acessado 2008 fev 14]. Disponível em: http://www.bioetica. catedraunesco.unb.br.

Artigo apresentado em 16/02/2008

Aprovado em 02/10/2008

Versão final apresentada em 29/10/2008 